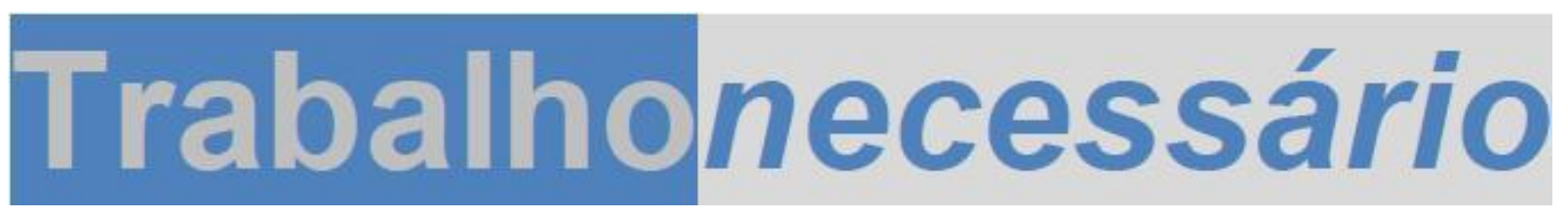

Issn: 1808 - 799X

ano 12, no $18-2014$

\title{
A FORMAÇÃO DA CLASSE OPERÁRIA INGLESA: HISTÓRIA E INTERVENÇÃO
}

\author{
Marcelo Badaró Mattos ${ }^{1}$
}

\section{Resumo}

O artigo faz uma sintética recuperação da ampla repercussão internacional e do profundo impacto no Brasil da obra do historiador inglês Edward Thompson. Analisando alguns escritos anteriores a 1963 e comparando-os às ideias-chave do clássico $A$ formação da classe operária inglesa, pretende-se demonstrar que as contribuições mais importantes de Thompson ao domínio especificamente histórico/historiográfico tiveram origem em suas intervenções no debate e na militância políticos.

Palavras-chave: E. P. Thompson; Teoria da História; Historiografia.

\section{Abstract}

The article makes a synthetic recovery of wide international repercussions and profound impact on Brazil of the work of the English historian Edward Thompson. Analyzing some of his writings, previous to 1963, and comparing them to the key ideas of the classic The Making of the English working class, the article intended to demonstrate that Thompson's most important contributions to the historical/historiograph domain had their origins in his interventions in political debate and militancy.

Keywords: E. P. Thompson; Theory of History; Historiography

\footnotetext{
${ }^{1}$ Professor Titular de História do Brasil na Universidade Federal Fluminense e pesquisador do CNPq.
} 


\section{Trabalhonecessário}

Issn: 1808 - 799X

ano 12, no $18-2014$

\section{Um livro e suas repercussões}

Em 1963 E. P. Thompson publicou The making of the English working class (A formação da classe trabalhadora inglesa, no título em português). A encomenda do livro chegou a Thompson depois de ter sido passada pelo editor através de Asa Briggs, que indicou John Saville para escrevê-lo e este, recusando a tarefa, repassou a indicação para Thompson, que a aceitou em 1959. Seu motivo para aceitar a tarefa, como alegaria depois, era estar precisando de dinheiro, mas é claro que se pode argumentar que escrever o livro seria, em grande medida, uma decorrência dos cursos que ministrava havia mais de uma década para as turmas de trabalhadores da WEA (a sigla em inglês da Associação Educacional dos Trabalhadores). A proposta do editor era originalmente muito distinta do resultado final. A ideia era escrever um livro voltado para estudantes universitários e de cursos livres, contando a história da classe trabalhadora inglesa entre as décadas de 1830 e 1940. Thompson solicitou ao editor incluir um capítulo introdutório sobre o período dos anos 1780 a 1830 e esse acabou por se tornar o conjunto da obra ${ }^{2}$.

Quando o livro foi publicado, Thompson era uma figura conhecida apenas pela intelectualidade de esquerda britânica por seu ativismo político. Em 1956 havia sido uma das mais destacadas lideranças da dissidência do Partido Comunista e, nos anos seguintes, um dos construtores do movimento político que ganharia o nome de New Left (Nova Esquerda), tendo desde então publicado uma série de escritos de polêmica política com o estalinismo, em periódicos como The New Reasoner (que fundara com John Saville e outros ativistas) e New Left Review (que surgiu da fusão do anterior com a Universities and Left Review). Embora já houvesse publicado uma obra de fôlego sobre a trajetória e as

\footnotetext{
${ }^{2}$ A esse respeito, ver SAVILLE, 2003, p. 119 e PALMER, 1996, p. 123.
} 


\section{Trabalhonecessário}

Issn: 1808 - 799X

ano 12, no $18-2014$

propostas de William Morris, não era conhecido em 1963 como historiador, nem tampouco como professor universitário, visto que desde o final dos anos 1940 se dedicava ao ensino de adultos de origem trabalhadora, em cursos vinculados ao Departamento Extra-Muros da Universidade de Leeds, quase sempre em cooperação com a WEA.

Face à falta de credenciais "acadêmicas" de Thompson, a repercussão positiva do livro e sua rápida transformação em obra de referência para a história da classe trabalhadora inglesa surpreendeu profundamente ao autor. Nas palavras de sua companheira Dorothy Thompson: "Nós ficamos surpresos com a recepção que teve o livro de Edward. Nós não podíamos acreditar que havia mais pessoas a nossa volta que iriam produzir uma resenha favorável"(THOMPSON, D., 2000, 8).

Em alguns anos o livro seria publicado em versão de bolso, com altas tiragens, e começaria a ser traduzido para diversos idiomas, ganhando circulação amplíssima. Eric Hobsbawm, citando indexadores de língua inglesa, afirma que $A$ formação foi o livro de história mais citado do século XX (HOBSBAWM, 1993).

Avaliações de críticos, assim como de admiradores, são hoje quase unânimes em reconhecer que a obra foi um marco. Bryan Palmer, em sua biografia intelectual de Thompson, afirma que a grande virtude de $A$ formação reside na "irrefutável ruptura a que forçou a literatura histórica", pois a partir daquela obra "não mais se poderia impor a formação das classes, tanto por radicais como por reacionários, como um reflexo mecânico de mudanças de ordem econômica (PALMER, 1996, 127)". Já Marcel van der Linden, que defende a necessidade de superação de limites da abordagem de Thompson em $A$ formação (especialmente por considerar que Thompson menospreza as ligações internacionais da formação do proletariado inglês), reconhece que a obra foi a mais importante referência da passagem de uma "velha" a uma "nova história do trabalho", qualificando-a como uma "revolução intelectual"(LINDEN, 2009, 3).

TrabalhoNecessário - www.uff.br/trabalhonecessario; Ano 12, № 18/2014. 


\section{Trabalhonecessário}

Issn: 1808 - 799X

ano 12, no $18-2014$

Pode se dar alguma razão à crítica de Van der Linden, mas se a abordagem de Thompson sobre a classe trabalhadora inglesa é, em certos momentos, por demais "insular", a avaliação de sua obra como uma ruptura/revolução intelectual extravasou em muito os limites do debate inglês. É o que percebe Rajanarayan Chandavarkar, em um artigo cujo objetivo era examinar "a influência do trabalho de Thompson nos estudos sobre a classe trabalhadora na história indiana". O artigo chama a atenção para alguns paradoxos levantados pela grande influência de Thompson entre os historiadores indianos. E um dos mais interessantes é justamente o que se explicita quando percebemos que os escritos de Thompson eram caracterizados por seu foco exclusivo na Inglaterra, porém "para alguém que estava tão atento às especificidades de um contexto social e cultural peculiar, é notável que a influência de seu trabalho seja global" (CHANDAVARKAR, 1997, 177).

Chandavarkar também apresentou um interessante caminho de análise para estudar a recepção do historiador inglês na Índia (e que pode nos orientar na discussão de outras recepções), procurando responder, basicamente, a três diferentes questões: como os historiadores indianos "leram" Thompson; o que eles "tiraram" dessas leituras; e como exploraram as possibilidades e expectativas abertas por sua teoria social "quando confrontadas com as evidências da história da classe trabalhadora indiana" (CHANDAVARKAR, 1997, 177-178).

Outros autores encontraram uma explicação para o sucesso do livro em regiões do Globo nas intenções políticas explicitadas por Thompson no famoso prefácio de $A$ formação. Scott Hamilton, desde a Nova Zelândia, em um livro recente e original, retoma uma passagem daquele prefácio - quando Thompson afirma que "causas que foram perdidas na Inglaterra poderiam ser ganhas na África e na Ásia" -, para lembrar que ao escrever sobre o processo de formação da classe trabalhadora nos primórdios da industrialização inglesa, Thompson estava tratando de um processo análogo ao vivido por boa parte do chamado

TrabalhoNecessário - www.uff.br/trabalhonecessario; Ano 12, № 18/2014. 


\section{Trabalhonecessário}

Issn: 1808 - 799X

ano 12, no $18-2014$

Terceiro Mundo que, nos anos 1950-1960, dava os primeiros passos em direção à industrialização acelerada. Assim, segundo Hamilton, "para muitos leitores, Thompson não está só descrevendo a história distante da primeira potência industrial do mundo; ele está dizendo alguma coisa sobre a situação de bilhões de seus contemporâneos" (HAMILTON, 2011, 123).

\section{No Brasil}

$\mathrm{Na}$ historiografia brasileira, o impacto da obra de Thompson foi no mínimo tão profundo quanto o apontado por Chandavarkar para o caso indiano. A hipótese de Hamilton é tentadora. Afinal, o Brasil é um país do Terceiro Mundo, ou melhor situando, uma periferia capitalista que se industrializou tardiamente em relação aos países de industrialização mais antiga. Nos anos 1960, entretanto, quando Thompson publicou seu livro, a industrialização brasileira vivia um estágio muito diferente daquela transição do artesanato à maquinofatura do contexto inglês a que se refere a obra. Apesar das características desiguais e combinadas do desenvolvimento capitalista na periferia envolverem a combinação de relações de trabalho supostamente mais "arcaicas" com aquelas consideradas mais "modernas", o paralelo com a situação inglesa da virada do século XVIII para o XIX só poderia ser válido para as principais cidades brasileiras no início do século $\mathrm{XX}$.

Ainda assim, é importante tentar entender as condições que explicam porque Thompson foi (e é) tão influente na historiografia brasileira. ${ }^{3}$ Com leitores no Brasil desde o final dos anos 1960, Thompson começa a ser citado sistematicamente pelos historiadores (e outros cientistas sociais) brasileiros a partir de meados da década de 1970. A formação, porém, só foi publicado em

3 Desenvolvo um esforço mais sistemático para discutir essa questão no quarto capítulo de MATTOS, 2012.

TrabalhoNecessário - www.uff.br/trabalhonecessario; Ano 12, № 18/2014. 


\section{Trabalhonecessário}

Issn: 1808 - 799X

ano 12, no $18-2014$

português em 1987. A recepção inicial do livro, incluindo sua tradução ao português, portanto, correspondeu aos anos finais da ditadura militar instalada no país em 1964 e ao início do processo de redemocratização.

Naquele contexto, uma das marcas da luta contra a ditadura, foi a (re) emergência, a partir de 1978, do movimento sindical na cena política brasileira, através de greves que enfrentavam os empresários e a política salarial da ditadura (núcleo de sua política econômica, que até ali fora o principal argumento da busca de legitimidade do regime). Um "novo sindicalismo", como ficou conhecido na época, que apresentava um discurso fortemente marcado pela defesa da "autonomia", dos sindicatos e da classe trabalhadora. Algo que foi entendido como uma novidade, pois as primeiras pesquisas universitárias sobre a temática dos trabalhadores, nos anos 1960/70, tenderam a enxergá-los como incapazes de uma ação política efetivamente autônoma, pois que limitados por uma estrutura sindical corporativista e um quadro político dominado, primeiro, pelo populismo e, depois, pelo autoritarismo ditatorial. Não cabe aqui comentar os limites daquelas interpretações, mas o fato é que Thompson, acentuando a "agência" da classe trabalhadora, foi tomado como referência fundamental para uma história do trabalho, que começava a enxergar os trabalhadores como "sujeitos de sua própria história".

Por outro lado, conforme o processo de redemocratização avançou e a as organizações sindicais e partidárias originárias daquelas lutas contra a ditadura foram se institucionalizando, os aportes teóricos de Thompson sobre lei e direito foram tomados como referência para o desenvolvimento de toda uma discussão que associava as lutas dos trabalhadores, ao longo do século XX brasileiro, à conquista e defesa de "direitos", civis, políticos e sociais (mais especialmente "trabalhistas").

Não se pode supor, porém, que a historiografia social inglesa em geral, e Thompson em particular, estivessem sendo semeados em solo virgem. Os 


\section{Trabalhonecessário}

Issn: 1808 - 799X

ano 12, no $18-2014$

historiadores universitários brasileiros, desde os formados pelas primeiras turmas do curso nos anos 1930/40, foram fortemente influenciados pela historiografia francesa. Assim, é possível entender que, se $A$ miséria da teoria é recebida como antídoto eficaz contra a rigidez do esquema estruturalista althusseriano, sua leitura se faz em paralelo e combinada à influência da terceira geração da "escola dos Annales", com sua ênfase na dimensão mental coletiva da história e sua predileção pelos temas microscópicos e "marginais". Também no interior desse quadro combinaram-se entre os leitores de Thompson no Brasil, sua influência com a de autores como Michel Foucault. Quando, a partir dos anos 1990, a chamada "história cultural" de matriz francesa passou a dominar a historiografia brasileira, Thompson chegou a ser definido como "uma espécie de 'versão marxista' da história cultural", entendida como uma evolução da "história das mentalidades" (VAINFAS, 1998, 155). Indo além, um outro historiador ilustre chegou a dizer que "o trabalho de Thompson poderia estar na Nova História" (NOVAIS, 2002, 130).

Podemos dizer que hoje Thompson representa mais um autor na estante das obras lidas em cursos universitários de História no Brasil, sendo reconhecido por alguns como "um clássico" e por outros como o "equivalente" inglês de alguma nova moda intelectual francesa. Como "clássico", perde-se a vitalidade de seus trabalhos e acaba dominando uma visão de sua obra como coisa do passado, mais uma etapa da história da historiografia que se precisa conhecer por mera erudição acadêmica. Como equivalente a qualquer outra coisa, perde-se a particularidade da filiação a uma determinada tradição teórica, a qual Thompson explicitamente reivindicou. 


\section{Trabalhonecessário}

Issn: 1808 - 799X

ano 12, no $18-2014$

\section{Marxismo e compromisso político}

Quanto a este último aspecto, a relação entre a obra de Thompson e o marxismo fica eludida, ou sua filiação teórica é mitigada por uma suposta heterodoxia. Por certo que afirmar que Thompson era um marxista resolve muito pouco diante dos diferentes entendimentos do que venha a ser o marxismo, ou dos diferentes marxismos. Thompson, porém, foi claro em definir a herança que reivindicava como a de crítica ativa e razão aberta do materialismo histórico, apresentada em oposição ao marxismo como uma teologia vulgar e dogmática que havia dominado o cenário desde a estalinização do movimento comunista mundial (com raízes no pensamento marxista dominante na II Internacional). Assim, em A miséria da teoria, afirmou que existiam na verdade "duas tradições" irreconciliáveis do marxismo:

O fosso que se abriu não foi entre diferentes ênfases ao vocabulário de conceitos, entre esta analogia e aquela categoria, mas entre modos de pensar idealista e materialista, entre o marxismo como um fechamento e como uma tradição, derivada de Marx, de investigação e crítica abertas. O primeiro é uma tradição de teologia. O segundo uma tradição de razão ativa. Ambos podem buscar uma certa autorização em Marx, embora o segundo tenha credenciais imensamente melhores quanto à sua linhagem (THOMPSON, 1981, 208).

Por outro lado, Thompson não pode caber numa estante de obras acadêmicas canônicas petrificadas. Sua obra é exemplo de explicitação do compromisso entre pesquisa sistemática sobre o passado e projeto de sociedade. ${ }^{4}$ Ou seja, o conteúdo de intervenção presente em seus escritos não pode ser menosprezado, já que Thompson era, assumidamente, um historiador militante. Quando afirmo isso, acredito estar em sintonia com a própria concepção

\footnotetext{
${ }^{4}$ Estou aqui concordando inteiramente com Josep Fontana $(1998,10)$ - aliás, editor de várias obras de Thompson na Espanha -, quando afirma que toda análise do passado produzida pelos historiadores comporta uma dada leitura da realidade presente quando da realização de tal análise e um certo projeto de futuro (ainda que implícito).
} 


\section{Trabalhonecessário}

Issn: 1808 - 799X

ano 12, no $18-2014$

de intelectual de esquerda explicitada por Thompson. Afinal, em meados dos anos 1960, quando dirigiu fortes interpelações ao que começava a ficar conhecido como 2a. Geração da Nova Esquerda britânica, apresentou o apartamento das lutas sociais reais como principal motivo da debilidade de suas interpretações.

Sua crítica se dirigia ao que considerava um marxismo muito "sofisticado", mas preso a um "caráter teológico", importado do continente por intelectuais ingleses, que se combinava ao desenho negativo do contexto em que se davam essas "transições intelectuais desafortunadas":

"Isto foi seguido por um período especialmente castigado, em finais dos anos sessenta, em que existia um movimento intelectual de esquerda divorciado dos mais amplos movimentos populares, e que de algum modo convertia esse isolamento em virtude e não tomava medidas para travar contato com o movimento operário e outros movimentos populares de grandes dimensões" (THOMPSON, 1979, 300).

O que não significa dizer que possamos reduzir sua obra a uma ilustração com exemplos históricos de teses já previamente desenhadas para intervenção no presente. Pelo contrário, repudiando a ideia de que "toda história é ideológica, de direita ou de esquerda", Thompson afirmava o imperativo do método para o exercício apropriado da disciplina:

O que se intenta fazer é aproximar-se de problemas objetivos muito complexos do processo histórico (isto é o que fazia Marx). Isto supõe uma disciplina precisa que congrega o distanciamento e a objetivação - ser consciente das próprias inclinações, consciente das perguntas que está produzindo - e em grande parte do trabalho como historiador intenta-se ou bem fazer patente a intrusão das próprias atitudes e valores, se é que estão influindo, ou manter a distância e evitar que essa intrusão ocorra. De outro modo o que se faz é supor que o processo histórico não apresenta problemas para os quais as próprias convicções não tenham resposta. E isto não é certo (THOMPSON, 1979, 297).

\section{As origens de $\boldsymbol{A}$ formação}

Tenho insistido em afirmar, para um público oriundo de uma formação

TrabalhoNecessário - www.uff.br/trabalhonecessario; Ano 12, № 18/2014. 


\section{Trabalhonecessário}

Issn: 1808 - 799X

ano 12, no $18-2014$

universitária cada vez mais distante das lutas sociais das classes subalternas, na qual o discurso dominante no campo das Ciências Humanas e Sociais costuma estigmatizar qualquer tipo de militância como uma "contaminação" da "pureza" científica do trabalho intelectual, que as contribuições mais importantes de Thompson ao domínio especificamente histórico/historiográfico tiveram origem em suas intervenções no debate e na militância políticos.

Começo meu esforço para comprovar essa hipótese afirmando que a definição de classe apresentada em $A$ formação da classe operária inglesa foi construída nas suas intervenções no debate político na virada da década de 1950 para 1960.

Para corretamente avaliar tal debate é necessário situar o contexto de seu surgimento numa época em que a diminuição das disparidades na distribuição de renda e a ampliação no poder de consumo da classe operária dos países industrializados europeus levaram alguns cientistas sociais a proclamarem o fim da classe operária e a homogeneização das sociedades de capitalismo avançado, com a afirmação de uma onipresente "classe média".

Vários questionamentos à tese do "aburguesamento" operário foram mais tarde levantados, tendo por base estudos sobre a classe operária no mundo do trabalho, na esfera da produção, e não apenas no âmbito do mercado de consumo (GOLDTHORPE et alli, 1968). Nessa mesma linha de questionamentos

à tese da "afluência" operária, teve grande repercussão o estudo sociológico coletivo Coal is our life, em que se procurava estudar o impacto da nacionalização das minas de carvão e de outras reformas sociais promovidas pelos governos de maioria trabalhista do pós-guerra sobre a vida dos mineiros britânicos. As constatações do trabalho, que inspiraria toda uma série de estudos de

"comunidades operárias", enfatizavam que, apesar de todas as mudanças da "nova era", as divisões de classe mantiveram-se e sua percepção pelos mineiros havia mudado muito pouco. A partir de uma perspectiva de classe muito nítida, 


\section{Trabalhonecessário}

Issn: 1808 - 799X

ano 12, no $18-2014$

construída não apenas no espaço de trabalho, mas também na vida comunitária cotidiana, os mineiros de carvão continuavam a manifestar um profundo antagonismo contra os administradores das mineradoras e contra os privilegiados da sociedade em geral. Havia, entretanto, mudanças perceptíveis nas relações dos mineiros com o Partido Trabalhista, que apesar de bem votado nas comunidades mineiras parecia ter cada vez menos presença no cotidiano das comunidades. $^{5}$

Algumas das contribuições mais ricas para esta discussão viriam, porém, de uma abordagem que destacava as matrizes culturais do comportamento operário. Por esta época, Raymond Williams lançava as bases para o campo que viria a ser denominado dos "estudos culturais". Em suas obras de fins dos anos 1950 e inícios da década seguinte, Williams propunha uma abordagem, crítica em relação tanto à concepção empobrecida do marxismo (que ele inicialmente percebia como "o" marxismo) - que remetia a cultura para o reino da "superestrutura" -, quanto à visão idealista de cultura, tomada como produto das mentes educadas dos artistas e literatos. ${ }^{6}$

Richard Hoggart, em obra fundamental lançada em 1957, que contribui para que fosse apontado como fundador dos "estudos culturais", reconhecia a tendência a transformações profundas na cultura da classe operária, decorrentes da força dos produtos da chamada "indústria cultural". Porém, destacou a persistência de padrões de comportamento e valores tradicionais de classe, através da observação ativa da vida numa comunidade operária, algo que lhe era muito próximo, pois remetia a sua própria origem social (HOGGART, s.d.). $\mathrm{O}$ centro de suas preocupações no livro era a análise da circulação e repercussão

\footnotetext{
${ }^{5}$ DENNIS, HENRIQUES \& SLAUGHTER, 1969. (1a. ed. 1956). Um bom comentário sobre o livro em seu contexto pode ser encontrado em SAVAGE \& MILES, 1994, 4-5.

6 WILLIAMS, 1969 (1a. ed. Inglesa, 1958). Para uma síntese da contribuição de Raymond Williams ver CEVASCO, 2001. A trajetória dos estudos culturais é estudada pela mesma autora em CEVASCO, 2003.
} 


\section{Trabalhonecessário}

Issn: 1808 - 799X

ano 12, no $18-2014$

de livros e periódicos ditos populares, mas a obra de Hoggart foi além desse recorte e produziu uma rica descrição etnográfica da vida familiar e comunitária do operariado britânico, em que procura mostrar a leitura de classe a que são submetidas as novas situações sociais.

Nos anos anteriores, o Grupo de Historiadores do Partido Comunista Britânico - do qual participavam Maurice Dobb, Eric Hobsbawm, Cristopher Hill, Dona Torr e Victor Kiernan entre outros -, produzia uma série de contribuições que avançava em sentido análogo. Aqueles historiadores propunham, no interior dos marcos conceituais do marxismo, uma História não apenas econômica do capitalismo inglês, embora valorizassem a História Econômica. Forçando os limites da interpretação marxista dominante na época, ressaltavam a importância e a autonomia relativa de outros níveis de análise (político, social, cultural), destacando a relevância de estudos historicamente localizados em que tais níveis pudessem ser observados na sua dinâmica inter-relação. ${ }^{7}$

A partir de debates como os deste grupo e de sua experiência na militância política e na educação de jovens e adultos de origem operária, E. P. Thompson compôs, com seu $A$ formação da classe operária, um estudo que, pela ênfase na dimensão cultural da classe e pela riqueza de uma análise que reconstituía importantes aspectos da vida comunitária dos trabalhadores "pré-industriais", pode ser lido a partir de vários paralelos com outros trabalhos, como o estudo de Hoggart, a produção de Raymond Williams, ou as análises de Coal is our life, apesar das diferenças significativas quanto aos marcos conceituais. ${ }^{8}$

A produção de $A$ formação da classe operária respondia a um duplo comprometimento do autor com a polêmica, como ele próprio admite ao afirmar que a obra "ataca duas ortodoxias ao mesmo tempo, a história econômica

7 Sobre esse grupo, ver SCHWARTZ, 1982. Ver também, HOBSBAWM, 2002, 191 e ss. E KAYE,1984.

8 A comparacão com o trabalho de Hoggart foi sugerida por vários autores, como por exemplo, LEVE, et alli, 1992. 


\section{Trabalhonecessário}

Issn: 1808 - 799X

ano 12, no $18-2014$

quantitativa e o marxismo dogmático"(THOMPSON, 1997, 172).

Tratava-se, de um lado, da rejeição às teses da história econômica de matriz liberal, pautada pelo quantitativismo a-histórico, pela definição da capacidade de consumo como o centro da dimensão econômica da classe, pela ênfase nas escolhas individuais e pela recusa a admitir a exploração de classes. Um debate que naquele momento ganhava dimensões políticas evidentes, visto que o "grupo de Mont Pélèrin", origem do chamado pensamento neoliberal, liderado por Friedrich Hayek, havia tomado alguns anos antes a historiografia crítica sobre a revolução industrial e a situação da classe trabalhadora como alvo de seu ataque. Um seminário do grupo foi transformado em livro, em que se destacam artigos de T. S. Ashton, agregando uma introdução de Hayek. Na Introdução ele sustenta existir uma convergência entre a oposição dos Tories (conservadores) do século XIX ao industrialismo e a crítica dos socialistas dos séculos XIX e XX (que denunciavam a pauperização e as condições de vida deterioradas dos primeiros trabalhadores industriais). Hayek, com isso, contestava a "cientificidade" da análise dos socialistas, pois que para ele científica, é claro, era a avaliação positiva dos progressos trazidos pela indústria. Thompson menciona o livro em seu capítulo sobre "Exploração", deplorando a "mistura de teoria econômica e defesa especial" da "sociedade livre" ali apresentada e dirige o raciocínio central dos capítulos seguintes a uma refutação daqueles argumentos. 9

De outro lado, apresentava-se a recusa ao marxismo vulgar, que derivava diretamente a consciência e a ação coletiva da classe de seu lugar nas relações de produção, sem qualquer mediação, algo que Thompson procurará superar pela ênfase no conceito de experiência.

9 HAYEK, 1954. THOMPSON, 1987, 35 e ss. Esse debate é destacado por FORTES, 2006, 209210. Agradeço a Demian Melo por ter me chamado a atenção para essas referências e questões.

TrabalhoNecessário - www.uff.br/trabalhonecessario; Ano 12, № 18/2014. 


\section{Trabalhonecessário}

Issn: 1808 - 799X

ano 12 , no $18-2014$

Demonstrando a exploração de classes e sua apreensão pela consciência da classe trabalhadora em formação nas primeiras décadas do século XIX, Thompson estava insistindo em contestar as teses liberais, explicando como as posições de classe se estabelecem a partir da produção (não do consumo) e como a classe trabalhadora se conscientiza da sua exploração pelos capitalistas tendo em conta seus próprios valores (e não os cálculos matemáticos de padrão de vida dos economistas liberais). Mas, a análise dos valores e tradições culturais que, confrontados com uma experiência singular, geraram uma dada conformação da consciência de classe, distanciava-o também do marxismo vulgar. Lições sobre o passado fundamentais para a crítica à noção de "afluência" operária no momento em que a obra foi escrita.

O resultado foi sistematizado na definição de classe, como processo e relação, que apresentou no Prefácio de $A$ formação, e que é, por certo, a mais conhecida passagem de seus escritos:

A classe acontece quando alguns homens, como resultado de experiências comuns (herdadas ou partilhadas), sentem e articulam a identidade de seus interesses entre si, e contra outros homens cujos interesses diferem (e geralmente se opõem) dos seus. A experiência de classe é determinada, em grande medida, pelas relações de produção em que os homens nasceram - ou entraram involuntariamente. A consciência de classe é a forma como essas experiências são tratadas em termos culturais: encarnadas em tradições, sistemas de valores, ideias e formas institucionais. Se a experiência aparece como determinada, o mesmo não ocorre com a consciência de classe (THOMPSON, I, 1987, 10).

\section{O fazer-se dos conceitos}

Thompson já havia explicitado essas propostas teóricas alguns poucos anos antes. Em 1960, no primeiro ano de existência da New Left Review, Thompson organizou uma coletânea de ensaios sobre o tema da "apatia" da classe trabalhadora inglesa, explicada quase sempre como resultante da "afluência". O último capítulo do livro, de autoria do historiador, foi publicado 


\title{
Trabalhonecessário
}

Issn: 1808 - 799X

ano 12, no $18-2014$

previamente no terceiro número da revista, com o título de "Revolution!". Uma série de comentários foi publicada no número seguinte e, no número 6, Thompson publicaria sua tréplica, com o título de "Revolution again! Or shut your ears and run". Nesse último artigo, encontramos praticamente toda a discussão sobre classe - como processo e relação, não como uma categoria estática, que se define a si mesma tanto quanto é definida, cuja consciência se constrói na identificação de interesses comuns e opostos aos de outra classe - que será resumida no prefácio de $A$ formação.

Rebatendo as críticas ao seu primeiro artigo, tanto do que denominava como "marxistas sectários", quanto dos antimarxistas, e especificamente nominando seus críticos do periódico trotskista International Socialist e o sociólogo estadunidense C. Wright Mills, Thompson explicava que:

\begin{abstract}
Nós deveríamos notar o caminho através do qual um tipo de reducionismo econômico desabilita a discussão de classe, tanto entre antimarxistas quanto entre marxistas sectários. Na verdade, as ideologias prevalecentes tanto no Leste quanto no Oeste são dominadas por uma caricatura aviltante do marxismo; muito embora, no primeiro caso, nós temos um retrato dos meios de produção espontaneamente gerando consciência e atividade revolucionária, com a classe trabalhadora aparecendo não como o agente, mas como intermediária de leis objetivas; ao passo que no segundo espaço a imagem é em muito similar, mas o motor da mudança foi retirado, e nós vemos todos os homens (exceto os 'intelectuais') como prisioneiros dos seus interesses econômicos, de sua 'estrutura' social, e do seu status. (...) Ambos argumentam a partir de uma noção estática de classe trabalhadora e de sua consciência característica (...) Ambos argumentam que o capitalismo 'afluente' está enxugando algumas das demandas da classe e erodindo a consciência de classe tradicional (THOMPSON, 1960, 23-24).
\end{abstract}

$\mathrm{Na}$ sequência do artigo, Thompson recupera justamente o momento de formação da classe que ele estava abordando na redação do que viria a ser $A$ formação, ou seja, o período dos anos 1780 a 1830, para chamar atenção para o fato de que a consciência de classe se formara num momento em que a maior parte da classe trabalhadora militante não era majoritariamente composta por operários fabris típicos. Afirmava então, como reiteraria três anos depois no livro, 


\section{Trabalhonecessário}

Issn: 1808 - 799X

ano 12 , no $18-2014$

que "para um historiador, uma classe é aquela que se define como tal por sua agência histórica" (THOMPSON, 1960, 24) · E recorreu à discussão de Marx no 18 Brumário sobre os camponeses detentores de parcela na França para afirmar que:

Para Marx, uma classe define a si mesma em termos históricos, não porque foi feita por pessoas com relações comuns com os meios de produção e uma experiência de vida comum, mas porque essas pessoas tornam-se conscientes dos seus interesses comuns e desenvolvem formas apropriadas de organização e ação comuns.(THOMPSON, 1960, 24)

Ainda no mesmo artigo, Thompson também apresentava sua argumentação sobre o caráter relacional através do qual a consciência de classe se definia, no terreno da luta de classes:

o conceito histórico de classe ou classes implica a noção de relação com outra classe ou classes; o que se evidencia não são apenas os interesses comuns no interior de uma classe, mas interesses comuns contra outra classe. E esse processo de definição não é apenas uma série de explosões espontâneas em um ponto da produção (considerando que isso é uma parte importante); trata-se de um processo complexo, contraditório, sempre mutável e nunca estático em nossa vida política e cultural, no qual a agência humana está implicada em cada nível (THOMPSON, 1960, 24).

"Agência", tradução comumente adotada no Brasil para o termo agency, associado à noção de que os homens são sujeitos de sua própria história, embora em condições que não escolhem, seria uma das mais fortes influências historiográficas que a obra de Thompson legou. Conforme percebe-se por essa citação, esta era outra ideia que já estava muito bem delimitada nas formulações políticas de Thompson, nos anos precedentes à redação de $A$ formação. Aliás, nesse caso, tratamos de uma ideia já desenvolvida quatro anos antes do debate sobre a "Revolução!" nas páginas da New Left Review.

Em 1956, no primeiro número de The New Reasoner, Thompson apresentou a proposta do "humanismo socialista", base política em torno da qual 


\section{Trabalhonecessário}

Issn: 1808 - 799X

ano 12, no $18-2014$

se agregaria a primeira geração da Nova Esquerda inglesa. No artigo, Thompson definia o humanismo socialista como a possível afirmação positiva de todo o movimento que, no Oeste ou no Leste, configurava-se em oposição à ideologia estalinista que havia dominado o movimento comunista internacional.

Ele é humanista porque coloca uma vez mais homens e mulheres reais no centro da teoria e da aspiração socialista, ao invés de retumbantes abstrações - o Partido, Marxismo-Leninismo-Stalinismo, os Dois Campos, a Vanguarda da classe trabalhadora tão caras ao Stalinismo. Ele é socialista porque reafirma a perspectiva revolucionária do comunismo, a confiança nas potencialidades revolucionárias não apenas da Raça Humana ou da Ditadura do Proletariado, mas dos homens e mulheres reais (THOMPSON, 1957, 109).

Desenvolvendo o argumento, Thompson se opõe ao stalinismo defendendo a agência humana negada pelo que já ali ele definia como o "irracionalismo" daquela ortodoxia (algo que retomaria com maior ênfase em seu Miséria da Teoria). Segundo seu argumento, "A primeira característica do stalinismo, então, é 0 anti-intelectualismo, o desprezo pela agência humana consciente no fazer histórico; e a revolta contra isso não é a revolta de uma nova ideologia mas a revolta da razão contra o irracionalismo"(THOMPSON, 1957, 115).

O artigo gerou polêmicas, que Thompson responderia alguns números depois na revista, num artigo sintomaticamente intitulado "Agency and choice - 1". Neste, reafirmava a crítica ao stalinismo e a importância da "agência". Definindo o filistinismo como a aceitação da inevitabilidade do mundo tal qual ele se apresenta, como uma capitulação ao senso comum, afirmava:

Hoje, esse filistinismo infectou os núcleos tanto da ideologia social-democrata quanto da comunista. Apesar das formas da infecção serem muito diferentes, ela produz em ambos um sintoma comum: a negação da agência criativa dos homens, quando considerados não como unidades políticas ou econômicas numa cadeia de circunstâncias determinadas, mas como seres morais e intelectuais, no fazer-se de suas próprias histórias; em outras palavras, a negação de que os homens podem, por um ato voluntário de vontade social, superar em alguma medida significativa as limitações impostas pelas 'circunstâncias' ou pela 'necessidade histórica' (THOMPSON, 1957, 109). 


\section{Trabalhonecessário}

Issn: 1808 - 799X

ano 12, no $18-2014$

Tendo conhecimento dessas intervenções políticas de Thompson no contexto dos anos 1950/60, entendemos melhor a origem das questões postas em $A$ formação. Por isso, seu estudo histórico tratava de explicar como a consciência de classe constrói-se historicamente através de formas específicas, conforme as peculiaridades que definem a experiência de classe em cada situação localizada. E o fazia para contrapor-se ao economicismo dos que creditavam à "afluência", vista em termos de acesso a mais bens de consumo, um limite à consciência operária, assim como à ortodoxia da II Internacional e da III Internacional sob Stálin, que afirmavam a derivação direta entre as contradições econômicas e a consciência de classe, transferindo a tarefa da revolução socialista para algum mecanismo "natural", independente da agência humana.

\section{Experiência educativa}

Experiência era uma chave nova apresentada por Thompson em $A$ formação para apresentar a sua discussão sobre a classe. Mas também nesse caso é importante perceber que tal noção não se formou fora da intervenção militante do historiador, como se brotasse da reflexão solitária do intelectual na elaboração de seu livro mais conhecido, em algum tipo de iluminação

"acadêmica". Aqui, porém, o espaço de desenvolvimento do conceito não foi propriamente a polêmica política direta, mas o engajamento no movimento de educação de adultos. Dorothy Thompson chama a atenção não apenas para a relação entre a redação do livro e a prática educativa de Thompson, mas também para a dimensão política que tal relação conferia ao livro. Segundo ela, o livro:

era baseado no tipo de docência que Edward esteve exercitando por dez anos. E o tipo de docência que fizemos o tempo todo. O que eu acho que produziu um tal avanço, e fez as pessoas verem o livro como tão revelador, foi que ele partia da perspectiva de que 0 que as pessoas comuns fazem é digno de interesse e atenção. Hoje isso é tão amplamente aceito que não é visto como revolucionário. Isso é basicamente uma 


\title{
Trabalhonecessário
}

Issn: 1808 - 799X

ano 12 , no $18-2014$

questão fortemente política de fato. (THOMPSON, D., 2000, 8)

Peter Searby recuperou relatórios de Thompson como "tutor" de cursos do Departamento de Educação Extra Muros da Universidade de Leeds, muitos deles em convênio com a Associação Educacional de Trabalhadores (WEA), além de ter recolhido depoimentos de alguns dos seus estudantes entre 1948 e 1965 (SEARBY, 1993). Em documento de discussão interna no Departamento, em 1950, Thompson expressava seu acordo com os objetivos político-educacionais da WEA, em termos que demonstram como a ligação entre a experiência de vida dos trabalhadores e as manifestações de sua consciência de classe era um elemento presente na forma como Thompson entendia seu trabalho docente:

\begin{abstract}
Em primeiro lugar, eles [a WEA] estão limitados por sua definição e estatutos políticos a uma ênfase nas necessidades educacionais de uma classe na sociedade à qual, por circunstâncias econômicas ou ambientais, é negado o acesso integral ao uso de outras instituições de ensino superior. Em segundo lugar, eles são dirigidos por uma ênfase específica - 'educação para propósitos sociais' - em fazer essa parcela da classe mais efetiva em atividades sociais. Em terceiro lugar, através do movimento de educação tutorial, eles estão especificamente preocupados em superar o divórcio entre as instituições de ensino superior e os centros de experiência social - entre 'os trabalhadores manuais e intelectuais' - existente em nossa sociedade. (...) Eles demandaram conhecimento com o objetivo de agir com maior eficiência em relação àquelas questões que sua experiência de vida solicita como mais urgentes. Sua atitude foi uma atitude de classe consciente, o que significa que foram conscientes o tempo todo, na busca da verdade e da ação social a favor dos interesses de sua própria classe em sua luta pela emancipação social (SEARBY, 1993, 5-6).
\end{abstract}

O respeito à experiência dos trabalhadores, aliás, é uma chave fundamental para entendermos de que forma a atividade de Thompson como professor de Literatura Inglesa e História foi um elemento central de seu aprendizado prévio à redação de $A$ formação. Assim, em um relatório sobre uma de suas turmas, de 1948-1949, quando Thompson tinha 24-25 anos, ele esclarece de que forma a experiência "tutorial" era importante para sua formação:

De modo geral, o tutor acredita ter aprendido mais o que ele transmitiu... e apesar de

TrabalhoNecessário - www.uff.br/trabalhonecessario; Ano 12, № 18/2014. 


\section{Trabalhonecessário}

Issn: 1808 - 799X

ano 12 , no $18-2014$

alguns erros iniciais, a classe aprendeu a trabalhar no espírito desejado na WEA - não como o tutor e a audiência passiva, mas como um grupo combinando diversos talentos e fundindo diferentes conhecimentos e experiências para um fim comum (SEARBY, 1993, 14).

Os depoimentos de seus ex-alunos são ricos em elogios à forma como Thompson os cativava em seus cursos, estimulando-os à leitura e à participação em classe, através de uma ênfase em apresentá-los ao conteúdo histórico e literário como algo que Ihes pertencia e fazê-los perceberem-se como parte ativa da história que aprendiam, tanto quanto faziam. Segundo Peter Thorton, um dos que com ele estudaram no início dos anos 1950:

As aulas de Edward Thompson... tinham esse efeito de fazer com que você percebesse que a história não era algo separado e a parte; ela era uma progressão da qual você era parte. Eu sempre sentia isso. E quando ele tratava de coisas como os tecelões manuais de Yorkshire, os ludistas, o desenvolvimento social da revolução industrial nesta parte do mundo, você muito rapidamente percebia o quanto você e a sua gente eram parte daquilo (SEARBY, 1993, 17).

A militância educacional na WEA era um dos elementos comuns às trajetórias de Thompson, Raymond Williams e Richard Hoggart. Além disso, a confluência, não isenta de tensão, entre os trabalhos daqueles intelectuais, na época, se dava também pelo caminho da militância comum no mesmo campo político da Nova Esquerda, constituído em aliança com movimentos sociais (como setores do movimento sindical, a esquerda do Partido Trabalhista e o movimento anti-nuclear, por exemplo). Os principais polos de aglutinação dessa militância eram periódicos, caracterizados não apenas pelos escritos de intervenção como também por algumas das mais lúcidas e instigantes análises das sociedades contemporâneas e pretéritas. ${ }^{10}$

10 Sobre o movimento da nova esquerda e seus periódicos - a fusão do New reasoner com a The university and left review, gerando a New left review - ver a entrevista do fundador e editor da revista nos primeiros anos Stuart Hall, 2003. Hall e uma série de outros protagonistas daqueles primeiros anos da Nova Esquerda registraram seus depoimentos em ACHER, 1989. 


\section{Trabalhonecessário}

Issn: 1808 - 799X

ano 12, no $18-2014$

Após a recepção surpreendentemente consagradora de $A$ formação, Thompson ainda se envolveria em inúmeras polêmicas no campo do marxismo, viveria uma fase de intenso ativismo antinuclear e voltaria a escrever importantes obras no campo da história. Uma produção cujas marcas principais foram a recusa às explicações simplistas e dogmáticas, às quais opunha a complexidade e conflitividade do processo histórico; o ardor do polemista em face das opções políticas e teóricas que considerava atravancarem as lutas da classe trabalhadora e a indissociável relação entre produção do conhecimento sobre a história e intervenção política militante. Obra polêmica, mas sobretudo instigante, capaz de expressar várias das mais ricas contribuições - assim como alguns dos impasses mais significativos - do marxismo no século XX. 


\section{Trabalhonecessário}

Issn: 1808 - 799X

ano 12, no $18-2014$

\section{Referências}

ARCHER, Robin et alli, Out of apathy: voices of the new left thirthy years on, London, Versus, 1989.

CEVASCO, Maria Elisa, Dez lições sobre Estudos Culturais, São Paulo, Boitempo, 2003.

CEVASCO, Maria Elisa, Para ler Raymond Williams, São Paulo, Paz e Terra, 2001.

CHANDAVARKAR, Rajnarayan, "'The making of the working-class': E. P. Thompson and Indian History", History Workshop Journal, 43, 1997.

DENNIS, N., HENRIQUES, F. \& SLAUGHTER, C., Coal is our life, London, Tavistock, 1969.

FONTANA, Josep, História: análise do passado e projeto social, São Paulo, Edusc, 1998.

FORTES, Alexandre, "Miríades por toda a eternidade: a atualidade de E. P. Thompson", Tempo Social, vol. 18, no. 1, 20, jun 2006.

GOLDTHORPE, John $\mathrm{H}$. et alli, The affluent worker: industrial attitudes and behavior, New York, Cambridge University Press, 1968, vol I.

HALL, Stuart, Da diáspora, Belo Horizonte, Edufmg, 2003.

HAMILTON, Scott, The crisis of theory: E. P. Thompson, the New Left and postwar Britsh politics, Manchester, Manchester University Press, 2011.

HAYEK, F. A., "History and politics", in Hayek (ed.), Capitalism and historians, Chicago, The University of Chicago Press, 1954.

HOBSBAWM, Eric, "E. P. Thompson obituary”, The Independent, 30/08/1993. HOBSBAWM, Eric, Interesting times. A twentieth-century life, London, Penguin, 2002.

HOGGART, Richard, As utilidades da cultura, Lisboa, Presença, s.d. KAYE, Harvey, The Britsh Marxists historians, New York, Polity Press, 1984. 


\section{Trabalhonecessário}

Issn: 1808 - 799X

ano 12, no $18-2014$

LEVE, Jean et alli, "Coming of Age in Birmingham: cultural studies and conceptions of subjectivity", Annual Reviews of Anthropology,1992.

LINDEN, Marcel van der, História do trabalho: o velho, o novo e o global, Revista Mundos do Trabalho, vol. 1, no. 1, jan-jun 2009 ( http://www.periodicos.ufsc.br/index.php/mundosdotrabalho)

MATTOS, Marcelo Badaró, E. P. Thompson e a tradição de crítica ativa do materialismo histórico, Rio de Janeiro, Edufrj, 2012.

NOVAIS, Fernando, "Entrevista", In MORAES, José G. V. \& REGO, José M., Conversas com historiadores brasileiros, São Paulo, Ed. 34, 2002.

PALMER, Bryan, Edward Palmer Thompson: objeções e oposições, São Paulo, Paz e Terra, 1996.

SAVAGE, Mike \& MILES, Andrew, The remaking of the britsh working class. 18401940, London, Routledge, 1994.

SAVILLE, J., Memoires from the left, London, Merlin Press, 2003.

SCHWARTZ, B., "The People in history: the Comunisty Party Historians Group 1946-1956", In JOHNSON, R. et alli, Making histories: studies in history, writting and politics, London, Hutchinsosn, 1982.

SEARBY, Peter, RULE, John \& MALCOLMSON, Robert, "Edward Thompson as a teacher: Yorkshire and Warwick", in RULE, J. \& MALCOLMSON, R. (eds.),

Protest and survival. Essays for E. P. Thompson, London, The Merlin Press, 1993.

THOMPSON, Dorothy, "Interview with Dorothy Thompson, Conducted by Pamela J. Walker", Radical History Review, no. 77, New York, 2000.

THOMPSON, E. P. "O espírito whig sem o elitismo: entrevista com E. P. Thompson", in BOURDIEU, Pierre et alli, Liber 1, São Paulo, Edusp, 1997.

THOMPSON, E. P., "Revolution again! Or shut your ears and run", New Left Review, no. 6, London, nov-dec 1960.

THOMPSON, E. P., "Socialist Humanism. An Epistle to the Philistines", The New reasoner, A quarterly journal of socialist humanism, Vol. 1, num 1, Summer, 1957. 


\section{Trabalhonecessário}

Issn: 1808 - 799X

ano 12, no $18-2014$

THOMPSON, E. P., "Una entrevista”, In Tradición, revuelta y consciencia de clase: estudios sobre la crisis de la sociedad preindustrial, Barcelona, Crítica, 1979. THOMPSON, E. P., A miséria da teoria, ou um planetário de erros: uma crítica ao pensamento de Althusser, Rio de Janeiro, Zahar, 1981.

VAINFAS, R., "História das mentalidades e história cultural", In Ciro F. S. Cardoso

\& Ronaldo Vainfas, Domínios da História, Rio de Janeiro, Campus, 1998.

WILLIAMS, Raymond, Cultura e sociedade, São Paulo, CEN, 1969.

Recebido em maio de 2014.

Aprovado em junho de 2014.

TrabalhoNecessário - www.uff.br/trabalhonecessario; Ano 12, № 18/2014. 